\title{
Metáforas do Pensamento em Cena: a espetacularidade cotidiana de um território extraordinário ocupado por pessoas em restrição de liberdade
}

\author{
Graça Veloso \\ Universidade de Brasília - UnB ${ }^{1}$, Brasília/DF, Brasil \\ E-mail: jorgegracaveloso@gmail.com \\ João Timótheo Maciel Porto \\ Universidade de Brasília - UnB, Brasília/DF, Brasil \\ E-mail: titi.porto@gmail.com
}

\section{Resumo}

Trata-se este trabalho de uma reflexão sobre as relações estabelecidas nos espaços de restrição de liberdade, a partir de observações no sistema prisional do Distrito Federal. Ali, homens e mulheres transformam suas regras, contrarregras, interditos e metáforas, criadas para, a partir de seu estar juntos, em estetizações produzidas para, de alguma maneira, territorializar seus lugares de convivência. Sustentando-se nos pressupostos da Etnocenologia para as noções de espetacularidade e teatralidade, propõe apresentar uma epistemologia etnocenológica da prisão. Por esta perspectiva privilegia os diálogos com os estudos da linguagem, nas analogias das Metáforas da vida Cotidiana, propostos por George Lakoff e Mark Johnson e com as formulações de territorialidades e não-lugares, de Marc Augé. Parte de anotações sobre comportamentos corporais e linguísticos de pessoas em conflito com a Lei, observados, prioritariamente em penitenciárias, onde um dos autores, como membro do corpo sócio-educativo, é professor de Artes Cênicas.
This work is a reflection on the relations established in the spaces of freedom restriction, from observations in the prison system of the Federal District. There, men and women transform their rules, counter-rules, prohibitions and metaphors, created to, from their being together, into aesthetics produced to somehow territorialize their places of coexistence. Based on the assumptions of Ethnocenology for the notions of spectacularity and theatricality, this study proposes to present an ethnocenological epistemology of prison. From this perspective it privileges the dialogues with language studies, the analogies of the Metaphors of Daily Life, proposed by George Lakoff and Mark Johnson and the formulations of territoriality and non- places, by Marc Augé. Part of notes on body and language behavior of people in conflict with the Law, observed, primarily in prisons, where one of the authors, as a member of the socio-educational body, is a teacher of Performing Arts. 
Para a escrita deste artigo, partimos, inicialmente, das noções estabelecidas por Marc Augé (1994) para não-lugares como sendo espaços de rápida circulação ou de passagens. São antagônicos aos princípios de territorialidade, como os representados pelo lar, pela residência, ou por qualquer outro espaço privado ou personalizado. Por essa perspectiva, ao analisar o sistema de reclusão prisional, poderíamos fazer uma analogia das penitenciárias como, idealmente, não-lugares. Como espaços em que seres humanos seriam reeducados para serem reinseridos nas convivências sociais e societais, aqueles seriam somente lugares pelos quais os indivíduos passariam uma parte de suas vidas.

No pisar o chão da realidade concreta do sistema carcerário brasileiro, ocorre que, na prática, essa passagem não se concretiza. Homens e mulheres em restrição de liberdade terminam por transformar as prisões em verdadeiros espaços de territorialidade permanente. As prisões tornam-se lares, residências ou lugares de convivência social regida por regras, contrarregras, interditos, metáforas e estetizações próprias. Este estudo parte dessa realidade e levanta algumas alternativas encontradas pelos sujeitos observados, para tornar suas vidas um pouco mais possíveis. São pessoas em restrição de liberdade por conflito com a lei que acabam por tornar aquele não-lugar a que estão submetidos em espaços de pertencimento a um mínimo de territorialidade. E aqui, o que nos propomos é investigar quais são os mecanismos adotados para que isso se concretize, e apresentar uma possível epistemologia etnocenológica da prisão.

A presente investigação surgiu da curiosidade que desperta a observação cotidiana na relação com os presidiários. Isto se dá na experiência que um dos autores tem como professor de teatro no Sistema Prisional do Distrito Federal durante vinte e cinco anos. O que percebíamos, empiricamente, era um remodelar da linguagem e do pensamento do homem que ali chegava. Com o passar do tempo,

1 AFETO - Grupo de Pesquisa em Etnocenologia Universidade de Brasília - UnB. a nós outros ficava evidente que a sua percepção de mundo, e sua maneira de se colocar diante dos outros, se transformava. Os limites físicos impostos pelo aprisionamento despertam a atenção em todos os momentos. Como fala um dos internos entrevistados, que chamaremos de Zeca, para preservar sua identidade: "Grades, lages, cadeados e corredores sem saída, é esse o meu olhar. Meu mundo é limitado por muros, grades e cadeados" (Informação verbal). E sentíamos que esse olhar também é responsável pela produção da linguagem, tanto verbal quanto corporal, das pessoas em privação de liberdade. Foi então no intuito de verificar como se dá essa transformação que iniciamos este estudo.

Os dados foram coletados especialmente na Penitenciária da Papuda, espaço de reclusão masculina, localizada a aproximadamente 25 quilômetros do centro de Brasília. Além das observações realizadas durante longas sessões de discussão sobre alguns dos processos de ensaio, foram feitas rodas de conversa com seis internos, participantes do grupo de teatro dos internos ${ }^{2}$. Essas conversas geraram um acervo de aproximadamente dez horas de gravação e anotações com uma lista de termos e gírias usados no dia a dia dos falantes, todos do setor de ensino. Esses participantes têm idade média de vinte e seis anos e são todos do Ensino Médio.

Antes de iniciarmos as rodas de conversa foi solicitado que os integrantes do grupo de teatro se apresentassem e que eles escrevessem sobre quem eles eram, como eles viam a experiência na prisão, e como a situação social interferiu em suas histórias. Muito do que foi anotado sobre as metáforas por eles produzidas veio das respostas dadas a essas questões.

2 O grupo Unidos Pela Liberdade foi criado em 1999. Desde então foi responsável pelas montagens Preta Judite, uma babá desastrada, Os Comédias, Uma comédia, a propósito de uma tragédia, O voo sobre o oceano, As mal criadas, O tabaco que mata e A nova Arca de Noé. Com exceção de $O$ voo sobre o oceano (Bertolt Brecht), Uma comédia, a propósito de uma tragédia (de O último dia de um condenado, de Victor Hugo) e As mal criadas (adaptação da obra de Jean Genet), todas as outras são criações dramatúrgicas do próprio grupo. 
É pelo caminho das espetacularidades pelas quais se dão as convivências e conveniências sociais naqueles espaços, que seguimos com nossas reflexões. Parafraseando Armindo Bião ${ }^{3}$, podemos dizer que é no reconhecimento da alteridade, e nos consequentes diálogos que daí advém que os saberes estéticos aqui tratados se concretizam. Fato este que se reafirma quando esses se localizam nos estados de corpos em ação espetacularizada. E tomamos a Etnocenologia, Etnociência das artes do corpo e do espetáculo, como nosso referencial de fala. Vamos também encontrar em sua produção epistemológica um lugar privilegiado para as noções dialógicas entre o princípio de alteridade e as concepções sobre o olhar do outro, o que determina a noção de teatralidade ou de espetacularidade. Estes, que são dois conceitos muito caros aos fundadores da Etnocenologia, serão discutidos mais adiante, inclusive com a apresentação de suas derivações substantivas, adjetivas e adverbiais, a partir das proposições de Armindo Bião (1999).

Então propomos aqui uma aproximação entre uma análise sobre o olhar e sua produção de alteridades e os estudos da linguagem, nas analogias das Metáforas da vida Cotidiana, propostos por George Lakoff e Mark Johnson (2002). Isso na busca de uma compreensão de espetacularidades que aquelas pessoas em restrição de liberdade produzem em suas existências nos espaços prisionais do Distrito Federal.

Os espaços percorridos e vividos pela pessoa em privação de liberdade redefinem o seu corpo, sua ação e seu modo de pensar a si, ao outro e ao mundo, tornando essa geografia o seu próprio corpo espetacularizado. Para analisar essa corporeidade carcerária, devemos entender que as metáforas produzem conceitos, trazendo essas noções para um uso cotidiano. Elas, as metáforas, se organizam e se formulam pela vivência do dia a dia das pessoas

3 Armindo Bião sempre afirmava, em suas aulas no PPGAC/UFBA (Programa de Pesquisa e Pós-graduação em Artes Cênicas da Universidade Federal da Bahia), que "a arte dialoga com todas as áreas do conhecimento humano, mas não se submete a nenhuma delas" (Informação verbal). em seus contextos. E seus significados serão, então, o próprio reflexo do que, em essência, são a materialidade daquilo que elas representam para o grupo.

$\mathrm{Na}$ Etnocenologia, olhar e alteridade são elementos fundantes da relação que o pesquisador, partindo de sua trajetória, estabelece com seu recorte de pesquisa. Diferentemente do que geralmente ocorre nas ciências naturais, o pesquisador se coloca como um participante, registrando os fenômenos por um olhar de dentro para fora. Sua atuação se estabelece no âmbito da sua práxis na relação com os sujeitos observados e na escuta sobre suas práticas. E ainda nas regras internas que o grupo fazedor estabelece, incluindo aqui os léxicos próprios de cada fenômeno. Um interfere no outro, sem a preocupação da universalização de conceitos, como observa Dumas:

[...] percebe-se uma orientação nas pesquisas e textos produzidos sob a denominação da Etnocenologia pautada em alguns referenciais epistemológicos que direcionam a sua práxis. São referências que aparecem como importantes marcos discursivos na produção etnocenológica: o reconhecimento e o respeito às distintas alteridades culturais e a transdisciplinaridade na observação, reflexão e criação de objetos espetaculares (DUMAS, 2010, p. 3).

Nesse contexto de análise Etnocenológica, o olhar também deve ser observado pelo pesquisador, tendo como referência a liberdade epistemológica e criativa do objeto pesquisado. Alexandra Dumas, ao analisar o olhar, o transfere para a perspectiva também do pesquisador na sua relação com seu recorte:

[...] o objeto espetacular não é mais apenas um ponto fixo: uma festa, um rito, uma dança ou uma peça de teatro ou qualquer outro espetáculo, ele se desloca para um lugar móvel, o "olhar" ou os sentidos que se estabelecem entre um determinado objeto e quem se dispõe a pesquisá-lo (DUMAS, 2010, p. 3).

Assim, este artigo foi pensado a partir da observação sobre a relação com a alteridade e o olhar na produção de espetacularidades existentes nas 
falas e ações de pessoas em privação de liberdade. Observamos que a linguagem é esse elemento de produção do espetacular, ressignificando ideias e gerando novas formas de uso e vivência nos espaços prisionais. Nessa vivência, são produzidas metáforas que redimensionam o cotidiano dessas pessoas e criam novas espetacularidades.

Jean-Marie Pradier (1999) conceitua espetacular diferentemente do espetáculo. O espetáculo carrega delimitações e finitudes, sendo o que é apresentado para ser contemplado. O espetacular é um conjunto de coisas, uma forma de se comportar, de movimentar, de agir no espaço, de assimilar o outro e a si mesmo em estado de apresentação. Inerente ao homem, a natureza do espetacular, em produção é inacabada, por isso infinita. Pradier, ao definir o espetacular, informa que ele é: "[...] uma forma de ser, de se comportar, de se movimentar, de agir no espaço, de se emocionar, de falar, de cantar e de se enfeitar" (PRADIER, 1999, p. 24). Assim há a aceitação das diversas alteridades culturais, onde se vê as espetacularidades e a multiplicidade de olhares.

Armindo Bião, nos primórdios da Etnocenologia, ainda não muito distantes, visto que sua fundação se deu em 1995, na Maison des Cultures du Monde, em Paris, diferencia espetacularidade de teatralidade. Ele diz:

[...] teatralidade é quando o sujeito age e se comporta para a alteridade, com uma consciência mais ou menos clara, mais ou menos confusa de organizar-se para o olhar do outro". Já espetacularidade, [como comportamento pactuado entre ator e espectador] é "quando o sujeito toma consciência clara, reflexiva, do olhar do outro e de seu próprio olhar alerta para apreciar a alteridade" (BIÃO, 1999, p. 366).

Compreendemos que a melhor maneira de diferenciar uma da outra é pensar nas práticas cotidianas, como a escolha da roupa a ser usada no dia, como exemplo de teatralidade. Segundo este raciocínio, nos vestimos para o outro, mesmo que a consciência deste ato não seja clara e objetiva. Agimos teatralmente mesmo que não pactuemos com nosso espectador. Já a espetacularidade seria uma condição presente somente nos espetáculos propriamente ditos, que só acontecem na convenção estabelecida entre o atuante e seu espectador. Assim, o organizar-se para o outro é objetivamente reflexiva, consciência esta pactuada e intercambiada pelos dois.

Com o passar do tempo, entretanto, Bião (2007), redimensiona essas noções num recorte de três conjuntos de espetacularidades: o primeiro, que ele chama de substantiva, se localiza em todas as artes do espetáculo, onde existe um pacto consensual de consciência mútua sobre os estados alterados de corpo e comportamento de atuantes e seus espectadores. O segundo conjunto, que Bião denomina de espetacularidade adjetiva, se norteia pelo comportamento extraordinário dos atuantes, mesmo que não se estabeleça na relação com espectadores, como em todos os ritos que, na Etnocenologia, nominamos de "espetaculares". Estes são aqueles onde os atuantes prescindem de outras presenças para alterar seus estados de corpos. Bons exemplos são os rituais religiosos ou os desfiles militares que, independentemente de espectadores, podem acontecer.

Por fim, o terceiro grupo, das espetacularidades adverbiais, que ocorrem nas ações cotidianas. Aqui estão "os fenômenos da rotina social que podem se constituírem em eventos, consideráveis, a depender do ponto de vista de um espectador, como espetaculares, a partir de uma espécie de atitude de estranhamento, que os tornariam extraordinários" (BIÃO, 2007, p. 28). Essa adverbialidade torna-se elemento essencial de nossa análise, tendo nas práticas relacionais observadas entre sujeitos em restrição de liberdade as metáforas da vida cotidiana, aqui discutidas.

A figura de linguagem que transfere um termo para um conteúdo de significação com a finalidade de estabelecer representação de mundo por analogias, formando assim um modelo, denomina-se metáfora. Tais modelos levam à criação de um esquema aceito e estabelecido sócio-culturalmente por um grupo. Nesse modelo, segundo Lakoff e Johnson (2002), as metáforas penetram no cotidiano, não só na língua, 
mas no pensamento e ação, tornando-se assim um instrumento da cultura do grupo. Elas são produzidas e estruturadas pelo pensamento e ligadas aos processos mentais de vivência dos sujeitos. Como instrumento de apreensão da realidade, a metáfora é a vivência de uma substituição, uma coisa pela outra. Reestrutura e recria o cotidiano do indivíduo, motivando outras visões para as atividades diárias. Internaliza, assim, conceitos e noções por processos cognitivos em conformidade com a vida cotidiana.

A interpretação do mundo que nos cerca foi produzida com a nossa própria postura perante ele. Não é a nossa razão que determina solitariamente o nosso pensamento, mas a nossa atividade cotidiana também formula o que percebemos, criando assim novas relações e também produzindo novas metáforas. Não é somente a língua que formula os conceitos da vida cotidiana. A própria leitura que o usuário tem da língua e do seu mundo, sua postura individual e a sua compreensão do coletivo, são também elementos produtores de espetacularidades e maneiras de perceber e se colocar na vida. Em uma tribo onde os bens são comunitariamente usados, por exemplo, o valor do objeto está no seu uso e não de qual proprietário ele é. A metáfora, então, vai se referir ao valor do bem tão somente pelo seu uso comunitário.

O papel definidor das metáforas, para Ricoeur (2000), é que elas trazem uma aproximação do sujeito com o mundo, produzindo interpretações que levam a abordar a realidade como verdades de suas mentes individuais. Um conceito da vida de um indivíduo é produzido com base em suas vivências, criando o mundo conforme suas experiências e sua trajetória pessoal. Percebemos que o lugar também produz o espetacular.

Partindo então dessas noções, os termos que serão apresentados a seguir foram levantados nos contextos do Sistema Penitenciário do Distrito Federal, e as anotações foram feitas a partir das metáforas usadas nas relações ali estabelecidas. Foram registradas as formulações que possibilitam a produção das espetacularidades que caracterizam as falas e os comportamentos de indivíduos e grupos distintos, tanto em sala de aula, em diálogos com os internos, quanto durante as aulas de artes cênicas. Foram encontradas concepções de pensamentos e ações que surgem do próprio modelo que a prisão impõe às pessoas.

Pelo que observamos os homens e as mulheres em situação de cárcere são obrigados a realizar a substituição de um termo por outro ou a criação de uma maneira própria de pensar que organiza seus mundos, a partir de uma lógica da convivência no espaço restritivo. Assim, a fala e o comportamento são expressos a partir de modelos impostos por suas condições de subalternização: obrigatoriamente, falam quase em sussurros, andam em fila e com a cabeça e o olhar voltados para o chão.

Também registramos a espetacularidade que um dia de visita ou a movimentação nos corredores fazem: o que se vê é uma espécie de organização que, quando observada de fora, é quase uma "coreografia" espontânea. O que vemos são corpos que se retraem quando o próprio espaço atua sobre eles. São ações adverbialmente espetaculares: o andar em círculo, o banho, a alimentação, o cortar as unhas, (o que é feito com um único cortador pendurado na grade do controle, por onde todos passam). E mesmo na visita, quando verificamos que onde cabem duzentas pessoas se aglomeram seiscentas. Aí se vê uma espécie de dança, onde tudo se encaixa, quando os espaços são ocupados em uma divisão silenciosa e respeitosa. Todos os familiares são abrigados em um espaço mínimo, chamado de rodoviária, que é a parte coberta do pátio.

Os espaços são rigorosamente respeitados, até a conversa de um não pode ser ouvida pelo outro. Um só pode entrar no canto de outro se for convidado. Os passos entre uma quebrada (como definem seus territórios) e outra demandam uma minuciosa movimentação corporal para evitar invasões e pisadelas nos lençóis, usados para a visita se sentar. É uma verdadeira colcha de retalhos, cada qual em seu quadrilátero, simultaneamente ocupado pelos visitantes.

Nesse contexto são ouvidas palavras e termos que produzem o pensamento e a espetacula- 
ridade daquelas pessoas. É como se estivessem numa grande feira livre, onde cada um nos oferece possibilidades de entender seus mundos pelas metáforas que nos apresentam. Quando observados e escutados, na ordinária de seu dia-a-dia ou no extraordinário dos dias de visita, ressaltam-se, com toda sua força, os sentidos dados a uma produção léxica própria. Consideramos que, por adquirirem significados muito próprios aos grupos ali estabelecidos, são maneiras de estabelecer territorialidade e sentimentos de pertencimento àquele não-lugar. Assim aparecem as denominações dadas para cada um de seus significados. Por reconhecer o léxico utilizado pelos aprisionados como próprio de suas interações, mantivemos cada termo, cada palavra ou frase na forma como foi escutado e registrado. Elencamos, a seguir, muitas das expressões anotadas e que se tornaram a razão deste estudo:

CRIME - termo corriqueiro no falar das pessoas em restrição de liberdade. Crime é como uma pessoa. "O crime é amigo", "o crime dá conselho", "o crime me ensinou, não sou mais ladrão", "não sou mais do crime", "o crime me pegou", "eu fui levado pelo crime", "o crime me trouxe para este lugar", "entrei na vida do crime", "o crime leva a gente a loucuras". Assim, podemos personificá-lo como algo que traz uma produção simbólica de ação e de espetacularidades para "a vida do crime", que é tratada como uma personagem. Ela age sobre cada indivíduo ali presente.

MURO - segue uma lógica não muito usual: "o muro é um conselheiro, eu aprendi muito com ele", "o muro é o meu professor", "a gente se distrai, quando vê, lá tá o muro falando com a gente", "esse muro já ouviu coisas!", "o muro olha pra mim", "a gente põe a bunda no muro e esquece da vida", "muito da minha vida aprendi com o muro". QUENTINHA ou CROMADA - também pode ser personificada na linguagem dos falantes do Sistema: "a musa dos ladrões", "lá vem a cromada", "vou pagá uma quentinha", "a cromada não veio hoje", "todo ladrão espera a sua musa", "a roupa dela é cromada", "a cromada não revela o que tem dentro", "todo dia eu espero e ela vêm ao meu encontro", "a quentinha só traz notícias boas", "sem ela nós não vive", "só ela me acalma", "a cromada é especial", "há uma espécie de amor e ódio entre a gente", "só a cromada me entende". No mundo masculino da prisão, a quentinha personifica uma mulher que traz alegrias e algumas decepções, mas todos querem e desejam: "sem ela não vivemos".

CASA - encontrada como elemento de territorialização, há uma ideia de que a prisão se personifica em casa, como nos exemplos: "a casa conspira", "a casa não teve pena dele, transferiu ele de cela", "a casa investe é no ladrão cagueta", "o chegado brigou no pátio a casa vai sabê", "eu só falo o que a casa quer ouvir, eu quero é paz, tô puxando a minha cadeia de boa", "na cadeia a casa é que manda", "a casa não incomoda com quem tá querendo puxá a cadeia". Talvez esteja aqui, na metáfora da casa, a maior demonstração de produção de sentido de pertencimento praticado pelos chamados apenados, internos do sistema. Como citado anteriormente, é no sentimento de que a casa vai, com o tempo, adquirindo a naturalização do lugar, que ela deixa de ser um não lugar. Adquire o caráter de personificação, de intimidade, de lar, inclusive com a utilização de objetos e signos de delimitação pessoal dos espaços individuais.

CADEIA - é a palavra de uso mais recorrente. $E$ pode ser empregada de diversas maneiras e significados. A personificação é uma transferência comumente usada, como nos exemplos: "a cadeia ensina o ladrão de galinha a ser doutor no crime", "a cadeia leva o cara à neurose, o cara vira 22 (louco)", "só quem tá na neura sabe o que a cadeia fala", "o cara vem, e se ele não é o bicho, a cadeia mata ele", "com a cadeia não se brinca", "a cadeia ensina o ladrão a ser pior", "a cadeia ensina o ladrão a se calar", "o cara tava de boa só puxando a cadeia", "a cadeia para o ladrão que quer recuperar é como uma mãe: dá conselho", "o ladrão entra na cadeia e ela não deixa ele sair, mesmo tendo cumprido a pena", "a cadeia sabe tudo que acontece com o ladrão".

$\mathrm{Na}$ comunicação observada entre eles, há vários elementos que se articulam ou são acionados para que haja a interação. Como, por exem- 
plo, outras diversas personificações: "vida do crime", "você tá aqui na bruta", "entrou por uma aventura", "os irmãos é que dão força", "estou puxando a cadeia", "os guerreiros" e "a cadeia pesou".

$\mathrm{Na}$ utilização de suas inúmeras metáforas cotidianas, o falante traz a noção do agir, pressupondo também informações dos enunciados, levando em consideração os implícitos. Como afirma Armindo Bião (2007), a cultura humana, como tudo aquilo que produz sentidos para os grupos, se traduz muito pelas ações de corporeidades para a espetacularidade, seja ela substantiva, adjetiva ou adverbial. E é esta a compreensão que temos para a produção de uma cultura da população em restrição de liberdade.

Entendemos que as metáforas do cotidiano estão armazenadas no léxico mental do falante para reconstruir de alguma maneira as ações. Assim como o interno se reconstrói em seu relacionamento com o ambiente. "Lá em casa" pode ser a cela em que ele está. A noção de mundo para ele se restringe ao lugar que ele habita. Como se um macro mundo se fizesse deste micromundo, no lar de muros, grades e limitações, com suas espetacularidades próprias.

Podemos considerar que as pessoas que estão no micromundo da prisão entendem que estão no mundo. Ele é completo. Todas as ações então vão sair daí, toda a rotina das pessoas num ambiente não prisional se expressa na prisão. Como aparato cognitivo, as metáforas e as ações produzidas por elas se tornam essenciais para a compreensão do mundo entre muros e da cultura que emerge desta estrutura linguística, metafórica e espetacular. A linguagem produzida a partir da situação dos corpos dos internos é uma necessidade, não somente intelectual, mas também física. É uma linguagem da necessidade, da corporificação dos espaços físicos, da intelecção da experiência do mundo das grades.

A consciência operacional vai além da percepção do fenômeno físico e encontra interpretações que somente a semântica não alcança neste universo. A entonação, o ritmo da fala, o movimento corporal, a posição social do falante, têm sentidos que somente o valor das palavras não poderia traduzir. É um conjunto vasto que funciona para além da consciência, indo para um inconsciente inacessível, que somente quem vive entre grades, lajes e cadeados, pode produzir e dar significados.

Ao entrar no sistema prisional, há uma corporificação do ambiente e, deste, o surgimento das metáforas e da corporeidade que formulam o cotidiano, criando uma cultura carcerária, percebida pela alteridade e o olhar do observador. Novamente revisitando Bião, é buscando entender o meu olhar no olhar do outro que podemos pensar em uma epistemologia etnocenológica para este lugar, a grade, a cela, o pátio, a prisão.

As experiências naturais vão, com o tempo, formulando as metáforas e produzindo o mundo do presidiário, criando assim interpretações próprias para a sua realidade. Este mundo como é vivido por todos não é igual e uniforme. Cada pessoa produz a sua interpretação pessoal dessa estrutura, e de suas experiências do cotidiano. A função principal da metáfora e a espetacularidade é dar compreensão de um tipo de experiência vivenciada pelos corpos das pessoas em privação de liberdade, podendo criar similaridades com sua vida cotidiana, lá fora. Assim, as metáforas podem criar coerência entre as realidades do espaço com os corpos aprisionados, criando novas realidades. E lhes apresentar "verdades" que serão coerentes com a vida cotidiana, mesmo nos não-lugares, que, no decorrer dos minutos, das horas, dos dias, dos anos, transformam-se em verdadeiros espaços de pertencimento. E compreendemos que as espetacularidades de corpos em seus estados alterados metaforicamente, cumprem papel primordial para esse estado de vida naturalizada cotidianamente no sistema prisional.

Poderíamos então, por esses pensares, chegar a algumas considerações sobre o que fazem as pessoas em restrição de liberdade, observadas neste estudo, quando formulam suas metáforas, corporais, linguísticas e espaciais. Compreendemos que, ao criarem suas corporeidades espetacularizadas no ambiente, o que fazem, cotidianamente, é inventar maneiras de transformar o não-lugar da prisão em 
múltiplos lugares. À nossa percepção, são estratégias de sobrevivência em imaginárias apropriações para a criação de verdadeiros sentidos de pertencimento a alguma coisa, sentimento sem o qual a vida se torna muito mais difícil, quando não insuportável.

\section{Referências}

AUGÉ, Marc. Não-lugares: Introdução a uma antropologia da supermodernidade. Trad. Maria Lúcia Pereira. Campinas: Papirus Editora, 1994.

BIÃO, Armindo. Aspectos epistemológicos e metodológicos da etnocenologia: Por uma Cenologia Geral. In: Memória ABRACE I: Anais do I Congresso Brasileiro de Pesquisa e Pós-graduação em Artes Cênicas, Salvador: UFBA, 1999; p. 364 - 367.

Um Trajeto, Muitos Projetos. In: BIÃO, Armindo (Org.). Artes do Corpo e do Espetáculo: questões de Etnocenologia. Salvador: P\&A Editora, 2007.

DUMAS, Alexandra Gouvêa. Etnocenologia e comportamentos espetaculares: Desejo, necessidade e vontade. Anais VI Congresso ABRACE. Disponível em: http://portalabrace.org/vicongresso/etnocenologia/Alexandra_Gouvea_Dumas_-_Etnocenologia_e_comportamentos_espetaculares.pdf. Acesso em: 02 fev. 2020.

LAKOFF, George.; JOHNSON, Mark. Metáforas da vida cotidiana. Campinas, SP: Mercado das Letras; São Paulo: Educ. 2002

PRADIER, Jean-Marie. Etnocenologia. In: BIÃO, Armindo e GREINER, Christine. Etnocenologia: Textos selecionados. São Paulo: Annablume, 1999.

RICOEUR, Paul. A Metáfora Viva. São Paulo: Edições Loyola, 2000.

Recebido: 01/12/2019

Aprovado: 31/05/2020 